\title{
„Wässern“ einer Harnleiterschiene
}

\section{Zur Verbesserung von Gleiteigenschaften und Minimierung von Patientenbeschwerden sollten Harnleiterschienen vor der Einlage benetzt werden - z. B. mithilfe der sterilen Innenverpackung.}

Experimentelle Untersuchungen zeigen, dass der hydrophile Gleitfilm von Harnleiterschienen die Gleiteigenschaften des Implantats dann verbessert, wenn diese bereits vor der Einlage benetzt werden. Hier werden nach einer mehrminütigen Benetzung eine Reibungsminderung bei Einlage sowie weniger Hämaturien und Schmerzen seitens des Patienten postuliert [1].

In der praktischen Umsetzung ist das „Wässern“ von Harnleiterschienen z. B. in einem sterilen Topf auf dem Instrumententisch umständlich, häufig wird auch nicht die komplette Harnleiterschiene befeuchtet.

Hier hat sich in unserer Hand das Nutzen der sterilen Innenverpackung des DJs bewährt: Sie wird nur ein wenig geöffnet, mit pyhsiologischer Kochsalzlösung gefüllt und mit einer Klemme wieder verschlossen. Der hydrophile Film des DJStents kann vor der Einlage „quellen“.

PD Dr. Andreas Wiedemann, Witten

Korrespondenz:

PD Dr. Andreas Wiedemann

Urologische Klinik

Evangelisches Krankenhaus

im Diakoniewerk Ruhr gGmbH

Lehrstuhl für Geriatrie

der Universität Witten/Herdecke

Pferdebachstr. 27

58455 Witten

awiedemann@diakonie-ruhr.de

Literatur

1 Laube N, Desai, C, Bernsmann F et al. Abstract NRW-GU 2015 Köln, 16.-17. 4. 2015, DOI: $1 ß 3205 / 15$ nrwgu005

Interessenkonflikte:

Beratungstätigkeit: Dr. Pfleger, Pfizer; Vortragstätigkeit: Allergan, AMS Deutschland, Astellas, Berlin-Chemie, Janssen, Lilly Deutschland, Dr. Pfleger, Pfizer, PohlBoskamp; Studienfinanzierung: AMS Deutschland
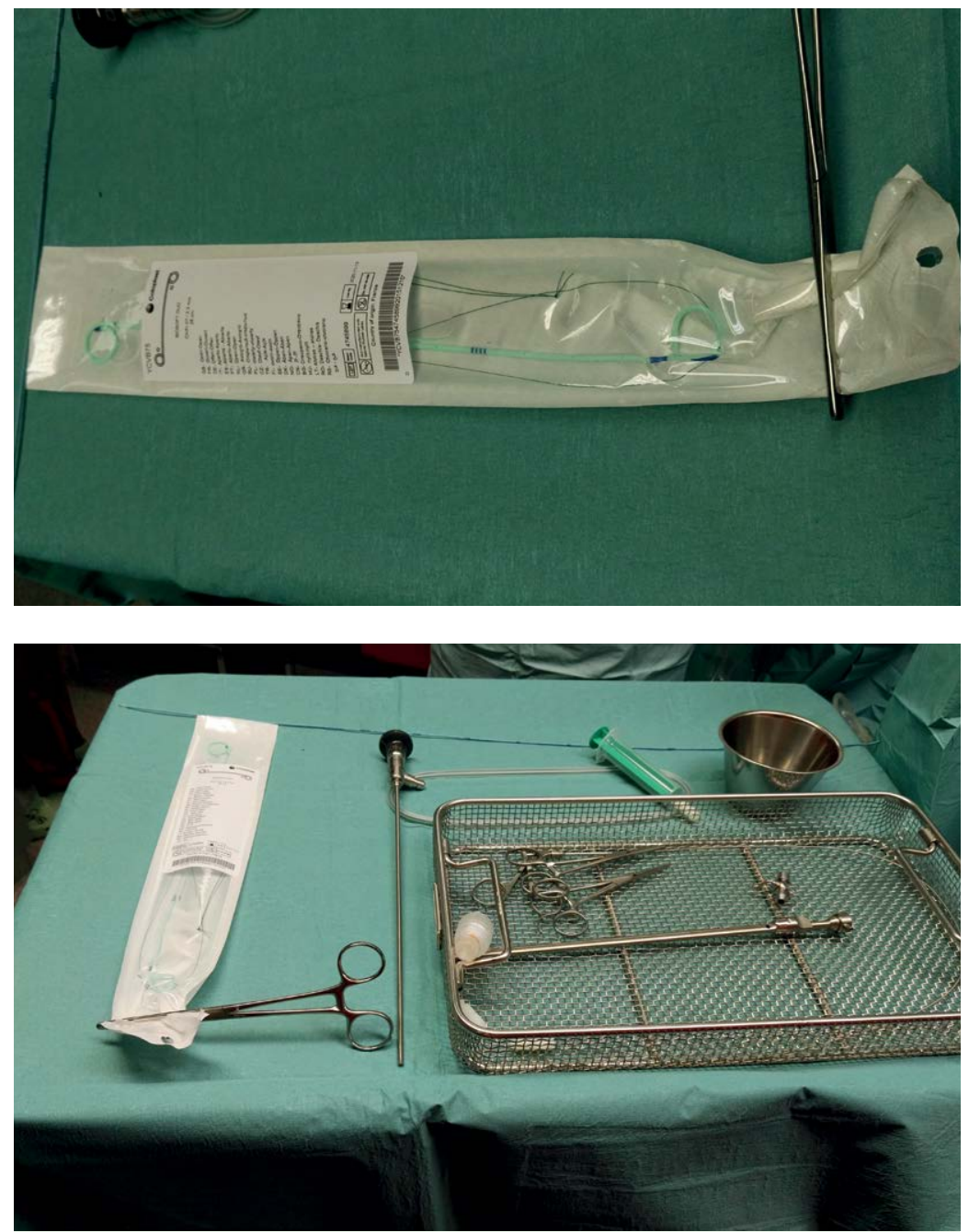

Die sterile Innenverpackung des DJ wird mit physiologischer Kochsalzlösung befüllt und mit einer Klemme verschlossen. Der DJ kann in Ruhe "quellen“. 